\title{
O Uso de Ferramentas para o Ensino de Computação: Um Foco no Ensino de Programação
}

\author{
Rodrigo Rodrigues de Lima e Milton Miranda Neto \\ Universidade do Estado de Minas Gerais \\ Ituiutaba/MG - Brasil \\ rodrigorl17@gmail.com,milton.neto@uemg.com
}

\begin{abstract}
Resumo: Ante a iminência de um mundo digital, este artigo traz como objetivo apontar quais são as ferramentas mais usadas atualmente para o ensino introdutório de programação, considerando para isto as ferramentas reutilizáveis. Para o alcance do mesmo foi empregada a metodologia de pesquisa documental e bibliográfica, que consiste, respectivamente, na utilização de artigos jornalísticos e acadêmicos. Basicamente, o que se percebe é que as ferramentas mais utilizadas atualmente são aquelas que concedem ao usuário uma experiência simples e interativa. É importante enfatizar que tanto as ferramentas como os temas abordados neste artigo são passíveis de estudos mais específicos, isto, a fim de se agregar maior conhecimento aos interessados no assunto.
\end{abstract}

Palavras-chave: Ensino da computação; Ferramentas de programação; Framework.

\section{Introdução}

Ante a uma sociedade cada vez mais inserida no universo high-tech (alta tecnologia), poder compreender, utilizar e se adaptar à tecnologia se tornou competência essencial para a evolução humana. Logo, inovar no que diz respeito a utilizar e criar tecnologia passou a ser uma aptidão necessária a todos [1, 2, 3].

Esta digitalização do mundo têm impactando diretamente na forma como as coisas são feitas, isto, em todas as áreas. Na área da educação, por exemplo, esta nova cultura fez com que outros conteúdos e métodos de ensino passassem a ser considerados, como a computação, pois se enxergou que se "a educação permanecesse off-line”, seria muito difícil a condução eficiente do indivíduo pelo caminho do aprendizado [1 n. p., 2, 3, 4].

Inserida no Brasil como ciência na década de 90, inicialmente a computação era vista como a inserção de recursos tecnológicos como ferramentas de auxílio à educação. Atualmente ela é vista como um conteúdo educacional essencial para a vida em sociedade, pois ela está presente em tudo, logo, seu ensino tornou-se uma questão de integrar o indivíduo ao mundo atual [1, 5, 7].

Em tempos onde a computação, seja como ferramenta de auxílio ou como ciência, é um elemento universal, a capacidade de produzir tecnologia tornou-se uma competência vigente, destacando assim a importância do seu ensino a todos. Seu ensino proporciona benefícios como a formação do raciocínio lógico e do pensamento computacional, contribuindo assim para a transformação social. No entanto, cabe mencionar que não há uma forma padrão para isto, nos levando a ponderar sobre as diversas formas existentes para o ensino da computação e a focar naquela considera como a mais alinhada a essa necessidade atual de produzir tecnologia, a programação de computadores, programação [7].

A programação se apresenta como agente de integração humana e tecnológica, e seu processo de ensino é capaz de gerar vários benefícios, como a fomentação de habilidades intelectuais e a experiência do trabalho em equipe, por exemplo, sendo a escolha da ferramenta tecnológica a ser utilizada para tal seu maior desafio. Em suma, ocorre que, assim como no ensino da computação, não há um padrão neste cenário, pois ensinar/aprender são atividades singulares e diretamente influenciadas pelos agentes envolvidos [2, 3, 4, 7, 8].

Softwares educacionais, animações e vídeos para a exemplificação e explicação de conceitos abstratos e ferramentas de programação, frameworks, são exemplos das formas utilizadas para ensinar programação, sendo este último escolhido como objeto de estudo deste artigo pela sua característica particular de oferecer funções básicas pré-prontas, onde o utilizador apenas adapta seu objetivo ao 'esqueleto' oferecido [2, 3, 5, 8, 9].

Assim, ante todo o exposto, mantendo nossa atenção no ensino da computação através da programação e nosso foco no uso de ferramentas como aliadas para este ensino, especificamente nas reutilizáveis, frameworks a nosso ver, o objetivo deste artigo é apontar quais são as ferramentas mais usadas atualmente para o ensino introdutório de programação, isto, a fim de desmistificar a ideia de que programar é algo só para experts em informática e de despertar o interesse do público para o tema, contribuindo com a sociedade de forma geral [8].

\section{Metodologia}

Neste artigo utilizamos a pesquisa documental e a pesquisa bibliográfica como forma de coleta de dados, onde a primeira se refere ao uso de artigos jornalísticos e de divulgação em sites relacionados ao assunto e a segunda ao uso de artigos publicados e/ou apresentados em congressos, revistas científicas e livros, os artigos científicos [10].

Inicialmente, através da plataforma de pesquisa Google e Google Acadêmico, realizamos uma busca por periódicos ligados a área da computação, usando o termo 'revistas de computação' como chave de busca. Em seguida, através da leitura dos títulos e resumos, realizamos uma busca por artigos relacionados ao nosso tema, o uso de ferramentas no ensino/aprendizagem da computação, e dos tópicos relativos a ele, como, por exemplo, o histórico da área no Brasil. Em seguida realizamos uma busca por publicações relacionadas ao tema utilizando termos como 'ensino de programação, ferramentas para ensinar programação, frameworks para 
ensino da programação', etc., o que nos levou a pesquisa de tópicos específicos, como das ferramentas mencionadas na seção 4 .

É oportuno mencionar, a fim de justificar o porquê da utilização desse método de pesquisa, que a pesquisa bibliográfica e a documental possibilitam um maior e mais diferenciado volume de informações, conferindo, a nosso ver, uma maior relevância ao artigo por reunir em si informações 'antigas' e atuais sobre o tema [11]. Portanto, a escolha dos artigos utilizados foi feita, considerando seu objetivo/ano/local de publicação, de forma a gerar conhecimento e dissipar ideias preconcebidas sobre o ensino e aprendizagem da programação. Assim, na busca pelo objetivo proposto, dividimos esse artigo em: Fundamentação Teórica; Resultados; Discussão; Conclusão e Bibliografia conforme segue.

\section{Fundamentação Teórica}

Na atualidade, o conhecimento sobre o que são e como utilizar os recursos tecnológicos tornou-se questão de sobrevivência, tornando evidente a necessidade do aprendizado de novos conteúdos. O surgimento dessa nova necessidade 'abriu as portas do mundo' para a inserção da tecnologia em vários âmbitos, na educação, por exemplo, essa inserção pode ser vista na introdução do ensino da computação na área. Conceituado como o ato de desenvolver e/ou aprimorar a capacidade do indivíduo para criar e/ou aperfeiçoar recursos tecnológicos, o ensino da computação é muitas vezes confundido com o ensino da informática, que consiste no ensino de como utilizar os recursos tecnológicos existentes, e não em desenvolver habilidades, como é o caso do primeiro [1, 4, 6, 12].

O ensino da computação como ciência no Brasil teve origem na década de 90 , com a implantação do curso de Licenciatura em Computação e Informática no Ensino Superior público pela Universidade Federal de Brasília (UnB). No início dos anos 2000 a disciplina ganhou espaço nas Instituições de Ensino Superior privado (IES), e em 2010, com o surgimento dos Institutos Federais (IF), passou a ter lugar no Ensino Médio brasileiro. No entanto, o ensino da computação nesse nível só aconteceu de fato dentro dos IF, pois ainda hoje são raras as instituições públicas de ensino que o ofereçam $[4,5,12,13,14]$.

O ensino da computação como disciplina no Brasil é ministrado predominantemente por escolas particulares e especializadas e nos Cursos Superiores e Técnicos, sendo importante ressaltar que, embora utilizando o termo informática, há registros de mobilizações em prol da implantação deste ensino nas instituições públicas de ensino a nível Fundamental e Médio desde a década de 70, embora não fique claro se a intenção era ensinar computação ou informática [4, 5, 12, 13, 14].

Podemos citar a cooperação ocorrida em 1975 entre a Universidade Estadual de Campinas (UNICAMP) e o laboratório do Instituto de Tecnologia de Massachusetts, Media LAB, a fim de "investigar o uso de computadores com a linguagem LOGO na educação de crianças”, como exemplo dessa mobilização. Outros exemplos relevantes são: a criação da Secretaria Especial de Informática (SEI), em 1979, uma organização que buscava discutir políticas nacionais para integrar a informática à educação, com ações como a implantação do projeto EDUCOM em 1983, e a realização do I Simpósio Brasileiro de Informática na Educação (SBIE), 1990, evento apontado como o núcleo das deliberações sobre a computação aplicada à educação [14 n. p., 16].

Estas mobilizações são vistas como marco dos esforços para implantar o ensino da computação nas instituições públicas de ensino, luta necessária para a transformação do ser humano, logo do mundo. São estas transformações que estimulam o processo mental no indivíduo, determinando quais as ações necessárias para resolver um problema, é o pensamento/raciocínio computacional, que encontra na programação o 'gênesis' de sua construção [7, 12].

O ensino de programação se apresenta no campo educacional mundial como o caminho para o desenvolvimento cognitivo, fato que por si só mostra sua importância. Presente na base curricular de ensino Fundamental e Médio de países como Estados Unidos, Inglaterra e Portugal, no cenário educacional brasileiro este ensino pode ser encontrado na forma de parcerias de projetos entre Estado e Município e/ou Município e Universidades; disciplinas optativas em colégios privados; Cursos Superiores; Cursos Técnicos nos IF e cursos em escolas particulares especializadas. Essas iniciativas são válidas, mas não são suficientes para garantir a inclusão de todos no mundo high-tech, pois são voltadas a grupos específicos, dificultando o acesso de alguns. Daí a importância da inserção da computação, logo do ensino da programação no ensino público, pois, na chamada 'Era do Conhecimento', é a capacidade de raciocínio crítico que garantirá a inclusão do indivíduo nesse novo mundo, o que só pode ser alcançado através do ensino [2, 4, 17, 18, 19, 20].

$\mathrm{O}$ pensamento crítico gerado pelo ensino da programação 'cabe em qualquer lugar', pois está presente em diversas áreas do desenvolvimento e aprendizado, sendo possível sua utilização para o ensino de qualquer coisa. Este ensino pode ocorrer de formas distintas e percorrendo diversos caminhos, como os da Matemática (jogos) e os da Tecnologia (frameworks), por exemplo, sendo o uso deste último considerado cada vez mais importante. Entre tantos benefícios, a utilização dos caminhos da tecnologia para o ensino da programação facilita o desenvolvimento de programas e aplicações; poupa tempo de trabalho; minimiza erros durante a programação e aumenta a qualidade do que é desenvolvido, e como exemplo deste 'caminho' podemos citar o uso dos frameworks [4, 20, 22, 23].

Por definição, os frameworks são "um conjunto de técnicas, ferramentas ou conceitos pré-definidos usados para resolver um problema [...] específico. Basicamente, é uma estrutura de trabalho que atua com funções preestabelecidas e que se adaptam à [uma] situação”, ou seja, que podem ser modificadas/reutilizadas conforme o necessário, possuindo várias linguagens de programação, funcionalidades, formas de interação, 
níveis de complexidade e finalidades de uso. [5, $15 \mathrm{n}$. p.; 17; 22, 24].

\section{Resultados}

Baseados no objetivo deste artigo, destacamos aqui cinco ferramentas de programação e frameworks utilizados na atualidade e considerados como os melhores para o ensino da mesma conforme o I do Code (centro tecnológico de ensino de programação) e a Hostinger (plataforma de hospedagem de sites de fama internacional). São elas: Blockly, Alice, Swift Playgrounds, Twine e Scratch, ambas consideradas como uma forma learning by doing de aprender, o aluno aprende ensinando o computador o que deve ser feito, isto é programar [24, 26, 27].

Tida como adequada ao ensino de programação a crianças e adolescentes, a Blockly, ou Google Blockly, é uma biblioteca visual gratuita para o ensino de lógica de programação inspirada na ferramenta Scratch. Ela é uma "biblioteca [...] que permite a integração de um editor visual de programação baseado em blocos em qualquer página da web ou aplicativo Android”, construindo as soluções computacionais de forma simples (comando arrastar e soltar), interativa de acordo com a necessidade do programador. Ela é responsável pela construção de vários projetos educacionais, como o Code.org, BBC micro: bit e o CodeBug, por exemplo, e seus resultados podem ser exportados em linguagem Java Script, Python, PHP, Lua e Dart [24, 26 p. 48].

Podendo ser utilizado no Ensino Superior como recurso introdutório à programação, o Alice é um ambiente de programação gratuito que, assim como a Blockly, tem seu foco no ensino de programação a crianças e adolescentes, porém de forma pouco mais avançada e com uma concepção orientada ao objeto. Estimulando o usuário à interatividade, ele usa o método de blocos para o ensino de programação 3D, possibilitando a criação de animações e narrativas interativas, jogos mais simples e aplicativos, disponibilizando resultados em linguagem Java, C++ Builder, Delphi e VB [24, 27, 21].

Por sua vez, a Swift Playgrounds é vista como uma das ferramentas gratuitas mais avançadas para o ensino da programação. De interface visual, moderna, interativa e divertida, ela é fundamentada em uma metodologia de blocos e possui sua própria linguagem. Sendo adequada ao ensino de conceitos de lógica às crianças e adolescentes de nível iniciante em programação, tem no fato de disponibilizar com excelência conceitos de programação considerados complexos a sua maior vantagem [24, 27].

Já o Twine é uma ferramenta visual gratuita que utiliza textos e imagens para ensinar lógica de programação para adolescentes a partir dos 12 anos, liberando seus resultados na linguagem HTML. Com ele iniciantes em programação podem facilmente criar jogos e histórias interativas e não lineares utilizando basicamente palavras e colchetes [24, 27].

Por fim, a linguagem de programação Scratch utiliza de recursos interativos visuais, sonoros e textuais para a criação de jogos, animações, histórias interativas, aplicativos, simulações, projetos científicos e tutoriais, fazendo uso da metodologia de blocos para ensinar lógica e transformar conceitos abstratos em algo sólido. Recomendada para crianças entre 8 e 16 anos, ela é uma ferramenta gratuita voltada para pessoas com pouca ou nenhuma vivência em programação, sendo mencionada em muitos estudos como uma ferramenta simples, intuitiva e agradável de trabalhar [4, 17, 24, 25, 27].

\section{Discussão}

Considerando as ferramentas aqui apresentadas se nota que, de forma geral, elas são ferramentas voltadas para pessoas com nível fundamental de alfabetização, ainda que não possuam conhecimentos amplos em programação, focando no ensino dos seus conceitos básicos à lógica de programação propriamente dita.

Usando recursos visuais, sonoros e/ou textuais, essas ferramentas apresentam como ponto comum ter o mesmo objetivo, facilitar o ensino/aprendizado da programação usando recursos e interfaces simples e interativas, o que, a nosso ver, é o que as caracteriza como sendo as melhores ferramentas para o ensino de programação.

Assim, respondendo ao objetivo proposto, podemos inferir que os frameworks mais utilizados na atualidade para o ensino da programação de computadores são, basicamente, aqueles que proporcionam interatividade ao aluno e simplifiquem seu aprendizado, como as ferramentas aqui apresentadas, visando, a nosso ver, desmitificar a máxima de que programar é difícil.

\section{Conclusão}

É importante mencionar que durante o desenvolvimento deste artigo pôde-se notar que é impossível falar da inserção do ensino da computação no Brasil, logo da programação, sem falar da sua implantação no ensino público. O que se entende é que, somente através da inserção dos mesmos no ensino público é que o ensino de computação/programação para todos será possível.

Ao pesquisarmos sobre as ferramentas utilizadas na atualidade para o ensino da programação, não podemos deixar de notar, embora não seja foco deste artigo, que todas as ferramentas aqui apresentadas são gratuitas, fato que nos fez questionar o porquê deste ensino a nível público ser predominantemente oferecido em Instituições de Ensino Superior e Institutos Federais, ponto que, a nosso ver, é passível de investigações mais amplas.

Nota-se também que através do ensino da computação, logo, da programação, é possível se estimular o pensamento crítico do individuo, sendo esta, a nosso ver, sua principal contribuição à sociedade, pois se entende que este é o princípio para que haja significativas transformações sociais.

Por fim, sugere-se uma pesquisa mais aprofundada acerca dos tópicos abordados neste estudo, assim como dos próprios frameworks aqui mencionados, pois, sem dúvida, ambos foram abordados de forma introdutória, e um estudo mais aprofundado sobre eles, a nosso ver, agregaria maior conhecimento. 


\section{Bibliografia}

[1] Construir Notícias. https://www.construirnoticias.com.br/educacao-x-geracaohigh-tech/. Acesso em 16/03/20.

[2] G1. https://g1.globo.com/sp/sorocaba-jundiai/especialpublicitario/ctrlplay/noticia/2019/07/26/ensino-daprogramacao-e-robotica-contribui-para-odesenvolvimento-das-criancas-e-adolescentes.ghtml. Acesso em 17/03/20.

[3] G1.

http://www.iplace-educacional.com.br/2018/08/14/ensinode-programacao-ja-e-realidade-em-escolas-brasileiras/. Acesso em 16/03/20.

[4] Ferreira, R.; Duarte, S. (2019) Ensino de Programação: trajetória histórico social e os avanços na cultura digital do Brasil. Revista Brasileira de Ensino e Tecnologia 12(1): 386-408. DOI: 10.3895/rbect.v12n1.7532.

[5] Lacerda, M. (2012) Informática como disciplina obrigatória na educação básica. Anais do VI Congresso Internacional de Linguagem e Tecnologia Online. UFMG.

[6] Nascimento, J. (2007) Informática aplicada à educação. $1^{\text {à }}$ edição. Universidade de Brasília.

[7] Matos, E. (2017) O ensino de computação como mecanismo de integração digital. Revista Computação Brasil 2(34): 48-53. SBC.

[8] Medium. https://medium.com/@thaisavelino/comoensinar-programa\%C3\%A7\%C3\%A3o-para-crian \%C3\%A7as-ou-iniciantes-sem-saber-programara2291bf8dc47. Acesso em 18/03/20.

[9] Becode. https://becode.com.br/frameworks-front-endmais-amados-segundo-github/. Acesso em 18/03/20.

[10] Gil, A. (2002) Como Elaborar Projetos de Pesquisa, 4 edição. Atlas.

[11] Souza, G. et al. (2017) A Gestão de Talentos Atualmente Adotada nas Organizações. Revista Cientifica Univiçosa 9(1): 540-545.

[12] Revista Direcional Escolas. https://direcionalescolas.com.br/ensino-da-computacaocurricular/. Acesso em 23/03/20.

[13] Lemos, A.; Freitas, De. (2017) Ensino da Ciência da Computação na Educação Básica: o que alguns países de fala espanhola estão fazendo, e o que podemos fazer no Brasil? Anais do VI Cong. Brasileiro de Informática na Educação, p. 873-882. DOI: 10.5753/cbie.wcbie.2017.873.

[14] Timetoast. https://www.timetoast.com/timelines/25048. Acesso em 23/03/20.

[15] Dinamica.blog. http://dinamicatreinamentos.com/blog/projetos/o-que-saoframeworks/. Acesso em 19/05/20.
[16] Castro, A.; Gimenes, I.; Castro Filho, J. (2019) Computação na Educação Básica: breve contextualização histórica. Revista Computação Brasil 1(41): 30-34. SBC.

[17] Silva Junior, S.; França, S. (2019) Programação para todos: análise comparativa de ferramentas utilizadas no ensino de programação. In: Princípios e Aplicações da Computação no Brasil. 1(1): Atena.

[18] Brasil Escola. https://educador.brasilescola.uol.com.br/noticias/escolasapostam-aulas-robotica-programacao-para-alunos-ensino/ 33259.html. Acesso em 24/03/20.

[19] Educação. https://revistaeducacao.com.br/2014/11/04/ensino-deprogramacao-e-aposta-de-colegios-em-todo-o-mundo. Acesso em 24/03/20

[20] Computação e Educação. https://blogcomputacaoeeducacao.blogspot.com/2016/05/a -import-ncia-do-ensino-da-programacao.html. Acesso em 24/03/20.

[21] Barros, E. A. R. (2012) Alice: uso do software no processo educacional junto aos cursos de engenharia. XL Congresso Brasileiro de Educação em Engenharia, p. 1-9.

[22] Mastertech. https://blog.mastertech.com.br/tecnologia/oque-e-framework-e-como-isto-influencia-naprogramacao/. Acesso em 26/03/20.

[23] Picanço, W. (2016) FDRobô: um framework didático para auxiliar o ensino de linguagem de programação adaptada ao método de aprendizagem cooperativa e competitiva. Dissertação de Mestrado. Programa de Pós-Graduação em Engenharia Elétrica. Universidade Federal do Amazonas.

[24] Idocode. https://idocode.com.br/blog/programacao/melhoreslinguagens-de-programacao-para-criancas/Acesso em $26 / 03 / 20$

[25] Hornink, G. G. (Org.). (2018) Contribuições da Computação para as Tecnologias Educacionais, $1^{\mathrm{a}}$ edição. Universidade Federal de Alfenas.

[26] Eli, P.H. (2017) Desenvolvimento de um Ambiente de Apoio ao Ensino de Algoritmos e Programação: usando Blockly. Dissertação de Mestrado. Programa de PósGraduação em Tecnologia e Comunicação. Universidade Federal de Santa Catarina.

[27] Hostinger Tutoriais. https://www.hostinger.com.br/tutoriais/linguagens-deprogramacao-para-criancas/. Acesso em 28/03/20. 